\title{
A POLÍTICA NACIONAL DE PROTEÇÃO E DEFESA CIVIL - PNPDEC NAS CIDADES BRASILEIRAS
}

\author{
Edson Ricardo Saleme ${ }^{1}$ \\ Renata Soares Bonavides ${ }^{2}$
}

Resumo: A Lei da Política Nacional de Proteção e Defesa Civil - PNPDEC, instituída por meio da Lei $n^{\circ}$ 12.608, de 10 de abril de 2012, estabeleceu a Política Nacional de Proteção e Defesa Civil- PNPDEC. Ela obriga a todos os municípios sujeitos a desastres e outros acidentes naturais elaborem seus planos diretores para melhor gestão de risco. Este marco legal modernizou permanentemente estratégias voltadas à prevenção de desastres e viabiliza formas de melhor gerenciamento deles com participação dos entes federativos e da sociedade com a liderança da União. O método empregado é o hipotético-dedutivo e a metodologia é a bibliográfica.

Palavras-chave: Plano diretor; PNPDEC; Desastres e Acidentes Naturais; Gestão de Risco; Prevenção.

\section{THE NATIONAL POLICY ON PROTECTION AND CIVIL DEFENSE - PNPDEC IN THE BRAZILIAN CITIES}

\begin{abstract}
This paper is to analyze the Law of the National Policy on Protection and Civil Defense - PNPDEC, instituted by the Law 12,608/2012, established in the National Policy of Protection and Civil Defense PNPDEC. It requires that all municipalities subject to disasters and other natural disasters must have master plans for better risk management. This legal framework has modernized strategies and enables forms of better management of them with the participation of federative entities and society with the leadership of the Union. The method used is the hypothetical-deductive method and the methodology is the bibliographical one.
\end{abstract}

Keywords: Municipal Plan; PNPDEC; Natural Disasters and Risks; Risk Managment; Prevention.

\footnotetext{
${ }^{1}$ Professor Doutor em Direito de Estado pela USP, professor do Curso stricto sensu em Direito Ambiental Internacional na Unisantos. Consultor do IBAMA. Advogado em São Paulo. Email: ricasal@uol.com.br ${ }^{2}$ Professora Doutora em Direito pela PUC-SP. Diretora e professora do Curso Stricto Sensu em Direito Ambiental Internacional da Unisantos. Advogada em Santos. Email: renatasbonavides@gmail.com
} 


\section{INTRODUÇÃO}

O objetivo deste trabalho é investigar a Lei da Política Nacional de Proteção e Defesa Civil - PNPDEC, instituída por meio da Lei $\mathrm{n}^{\circ}$ 12.608, de 10 de abril de 2012, nos planos diretores das cidades que possuam gestão de risco de desastres relacionados com fenômenos naturais. Este marco legal modernizou a maneira de abordagem ao tema, até então incipiente. Antes disso nenhuma norma se preocupava particularmente com os significantes desastres ocorridos de forma reiterada no Brasil. O que efetivamente motivou a confecção da norma foi sem dúvida o ocorrido na região serrana do Rio de Janeiro, em 2011, na qual se pôde observar a morte de mais de mil pessoas e um significante número de corpos não identificados. Essa perda de vidas ocorreu pela desídia na prevenção e também desconsideração do enorme risco que estavam correndo por ocuparem áreas perigosas, sujeitas a deslizamentos ou desabamentos. Essas circunstâncias revelaram a caótica realidade do país cujo território é extremamente vulnerável a desastres. Além disso, possui potenciais áreas de risco, isso sem contar que diante da situação climática vivenciada na atualidade, novidades a cada dia podem ser encontradas em termos de catástrofes.

A Constituição Federal de 1988, em seu artigo $5^{\circ}$, garante em seus incisos a inviolabilidade do direito à vida e à segurança. Nesse diapasão não há como se furtar em garantir a incolumidade dos cidadãos mesmo diante de ocupações irregulares ou estabelecimento de pessoas em locais inseguros que possam ser cenário de eventos trágicos como deslizamentos e desabamentos, cujo resultado pode ser fatal para as pessoas que ali estão. A atuação da Proteção e Defesa Civil desta forma pode intervir nessas ocupações e outras ações do gênero podem surgir com o intuito de reduzir desastres e assim mantendo vidas humanas envolvidas fora dos perigos inerentes a habitações fixadas em locais de risco.

A Política Nacional adotada trouxe tratamento adequado aos desastres naturais. Em seu conceito de proteção incorporou o conceito de proteção. Significa dizer que também aí se incluíram ações de prevenção, mitigação, preparação, resposta e recuperação relacionadas à proteção e a defesa civil, nos termos indicados no art. $3^{\circ}$ de seu texto. Esta Política Nacional estabelece uma atuação conjunta e articulada de todos os entes federativos com o objetivo de reduzir desastres e dar apoio às comunidades atingidas. Diante da criação da política criou-se, como conseqüência, um necessário Sistema Nacional de Proteção e Defesa Civil - SINPDEC, que agrupa não somente entes da administração pública federal, estadual e municipal, mas também entidades privadas de atuação marcante na defesa civil. 
A coordenação ficou a cargo da União, que deve sugerir ações apropriadas a serem tomadas em articulação com Estados e Municípios. As circunstâncias atuais, sobretudo diante das mudanças climáticas repentinas, que ora proporcionam excesso de chuvas e seca rigorosa, demandam atuação prévia para fortalecimento do Sistema Nacional de Proteção e Defesa Civil no Brasil, de forma a preparar a proteção da população contra os efeitos de desastres naturais. É fundamental, também, permitir que o país mantenha permanente a gestão de riscos, que garanta a implantação e permanência de estratégias voltadas à prevenção de desastres e ao melhor gerenciamento dos fatores de risco a eles associados. Além desse risco permanente de desastres há o risco de ameaças naturais se aliarem à vulnerabilidades sociais, diante da impossibilidade de se estabelecer um planejamento urbano adequado na municipalidade ou ainda problemas socioeconômicos que repetidamente nelas ocorrem.

No final do século 20, os processos de invasões e ocupações se aceleraram pelas interações de grupos que realmente necessitavam. Atualmente, além dessa demanda há outros grupos, quase milícias, que se apoiam na instabilidade governamental e em outros fatores para obter espaços cada vez mais significativos. No século 21, pode-se observar não só a continuação, mas também o aprofundamento e agravamento das crises iniciadas no século anteriore, bem como tentativas, na maior parte das vezes vãs, em buscar soluções impróprias e metas inatingíveis.

Diante desse panorama se quer esclarecer se a Lei da Política Nacional de Proteção e Defesa Civil - PNPDEC por meio da Lei $n^{\circ}$ 12.608, de 10 de abril de 2012, realmente trouxe efetivamente proteção aos municípios necessitados? É possível verificar se a prevenção, mitigação, preparação, resposta e recuperação relacionadas à proteção e a defesa civil estão sendo efetivamente tomadas? Quem são os atores efetivamente envolvidos e como podem incrementar seu papel no processo de defesa das catástrofes climáticas na população local?

Este trabalho será conduzido por meio da metodologia bibliográfica e documental. Seu método será hipotético-dedutivo e ao final as hipóteses abaixo indicadas poderão ser confirmadas ou não, de acordo com o desenvolvimento dos capítulos que se seguem.

\section{1 - NECESSIDADE DE PLANIFICAÇÃO INSTITUÍDA NO ESTATUTO DA CIDADE}

É possível afirmar que somente em 1969, por meio do Decreto n 64.568, é que se criou um dos primeiros grupos de trabalho com o objetivo de elaborar um plano de defesa permanente contra calamidades públicas, de acordo com o informado pelo Ministério da Integração

Rev. de Direito Urbanístico, Cidade e Alteridade | e-ISSN: 2525-989X | Porto Alegre | v. 4 | n. 2 | p. 85 - 100 | Jul/Dez. 2018 
Nacional (2018). No mesmo ano, o Decreto-Lei n. 950, instituiu o Fundo Especial para Calamidades Públicas (FUNCAP). No ano de 1970, com o Decreto n. 67.347, estabeleceu-se o Grupo Especial para Assuntos de Calamidades Públicas (GEACAP), com equipes preparadas para enfrentar situações extraordinárias decorrentes de desastres. Apesar dessas medidas preparatórias apenas em 1988 é que se estabeleceu a organização do Sistema Nacional de Defesa Civil (SINDEC), por meio do Decreto n. 97.274 que se refere ao reconhecimento de situação de emergência ou estado de calamidade.

Grandes cidades brasileiras ou com número significativo de habitantes já possuíam um instrumento que as capacitava a traçar metas e buscar apoios em projetos relacionados à infraestrutura local e com vistas ao desenvolvimento econômico e social: o plano diretor. Como afirmam Cymbalista e Santoro (2009), este instrumento não é algo novo, pois vinculava o repasse de recursos à existência de planos diretores "Nas décadas de 1960 e 1970, o Brasil assistiu a uma grande onda de construção de planos diretores nas grandes e médias cidades, em sua maioria, financiados pelo Serviço Federal de Habitação e Urbanismo (SERFHAU)".

O plano diretor ou plano diretor de desenvolvimento integrado, como atualmente também é conhecido, é constituído por um complexo de normas legais e diretrizes técnicas para o desenvolvimento global e constante do Município, como afirmou Hely Lopes Meirelles (1985, p.395-396), sob os aspectos físico, social, econômico e administrativo. O autor sublinha que as imposições desse plano são obrigatórias não só ao Município e aos particulares, como também deve ser observado pelos órgãos estaduais e federais que realizem obras ou serviços naquela localidade.

Antes da vigência da atual Constituição Federal, somente municípios de grande porte possuíam plano diretor. Atualmente é obrigatório, nos termos do art. 182 “caput" e seu $\S 4^{\circ}$ da CF. Somente municípios com mais de 20 mil habitantes e os que queiram instituir o PEUC (parcelamento, edificação e utilização compulsórios) para, posteriormente, implementarem o IPTU progressivo. O artigo 41 da Lei 10.257, de 2001, o Estatuto da Cidade aumentou o rol de municípios obrigados a criar plano diretor.

Na questão do conteúdo do plano diretor, José Afonso da Silva (2012, p. 145) esclarece que a elaboração da lei do plano diretor segue as regras do processo legislativo dado a lei orgânica municipal. Deve-se necessariamente garantir a presença popular em sua aprovação. As comissões da Câmara devem examinar e votá-lo desde que seja aprovado. O conteúdo do plano diretor é o conteúdo do próprio plano urbanístico. Esta lei pode ser auto-executável sem que outras leis inferiores sejam necessárias para sua implementação. Nesse sentido, pode ser 
geral, ficando sua atuação dependente de planos especiais, setoriais ou ainda de plano executivo.

Nesse sentido, o plano estabelece limites para os órgãos públicos e particulares que estão sujeitos as suas normas. Nulos são os atos praticados que não tenham conexão com elas. As limitações à propriedade privada são imediatamente impostas, assim como as obrigações de fazer ou não-fazer, como a regra non aedificandi, relacionadas às áreas indicadas como nãoedificáveis.

Em artigo dedicado ao tema plano diretor Jacinto Arruda Câmara (2014, p.322-343) chama a atenção para o fato de que a Lei 12.608, de 2012, introduziu novas matérias a serem abordadas pelo plano diretor de municípios, incluídos no cadastro nacional de municípios com áreas suscetíveis a ocorrência de deslizamentos e desabamentos de grande impacto, inundações bruscas ou processos hidrológicos correlatos. A lei modernizou e estabeleceu a obrigatoriedade de que as cidades que apresentem essas características tenham o plano.

Nestes casos, segue o autor, o plano diretor deve conter parâmetros de parcelamento, uso e ocupação do solo, de modo a promover a diversidade de usos e contribuir para que os munícipes tenham fórmulas para obter emprego e renda. Deve também conter um mapeamento indicando as áreas suscetíveis a desabamentos, deslizamentos, inundações bruscas ou processos geológicos ou hidrológicos correlatos.

A prática do planejamento nos municípios objetiva corrigir distorções de diversas óticas. Busca traçar mecanismos para que a gestão municipal desenvolva-se adequadamente e modificar situações indesejáveis que os munícipes estejam sofrendo. É também uma de suas funcionalidades viabilizar a ação quando apresente empecilhos institucionais mais comuns, pois sua instituição assegura o cumprimento de propostas a serem cumpridas em médio e longo prazo. Deve alcançar alguma longevidade e pode ser alterado antes, como muitas normas municipais disciplinam. Além disso, o plano diretor fundamenta e dá base aos planos orçamentários respectivos: plano plurianual (PP), lei de diretrizes orçamentárias (LDO) e a lei orçamentária anual (LOA). As diversas normas orçamentárias devem adequar-se aos rumos traçados pelo plano para que se realize uma boa administração com reflexos positivos para seus munícipes e seu entorno.

Diante desses elementos ULTRAMARI e REZENDE (2007) esclarecem que não se pode esquecer as variáveis socioambientais das cidades. Ademais, deve-se enfatizar a sustentabilidade urbana, o cenário de diversidade social que as caracteriza e a importância de se priorizar a função social da propriedade. Nesse contexto é claro que alguns elementos devem 
ser mais relevantes em um município que em outro, o que pode espelhar particularidades próprias de cada circunscrição. É certo que uma metodologia de elaboração em que não haja vinculações programáticas nem jurídicas conta com mais chances de sucesso

A metodologia de implementação do plano diretor deve contar com fases claras e definidas em que os agentes municipais possam estar envolvidos e também consultorias ou equipes que possam colaborar com uma boa gestão estratégica local. Além do planejamento, que demanda uma apuração detalhada da topografia local, sobretudo em cidades listadas no rol de cidades sujeitas a acidentes naturais também deve levar em consideração a gestão do planejamento. O afirmado por SAADI (1997, p.1) é efetivamente o que ocorre na prática: “O preço pago pela inobservância das mínimas regras impostas pela natureza tem sido muito caro para as populações e administrações dos centros urbanos. Além dos desastres ecológicos de vários tipos, as consequências estenderam-se, muitas vezes, a perdas de vidas humanas."

É certo que existe a visão do que o município deseja para seus munícipes e há também que se considerar as suas vocações e valores para traçar os objetivos que se quer alcançar. A vontade da comunidade local é essencial e seus respectivos controles para acompanhar a gestão do planejamento no que toca à medição de desempenho o que efetivamente garante o efetivo cumprimento do PEM. Isso estabelece a criação de indicadores para posterior medição, acompanhamento e avaliação.

As normas do plano diretor devem conduzir, nas palavras de Regis Fernandes de Oliveira (2005, p. 31), a um plexo normativo que permita o racional aproveitamento do solo urbano, planificando, desta forma, a vida naquela municipalidade. Desta forma se dará à propriedade sua respectiva função social, decorrente dos princípios estabelecidos globalmente, objetivando a melhoria da qualidade de vida em suas diversas dimensões.

Relativamente à importância que possui o plano diretor e seu papel imprescindível em cidades Carvalho Pinto (2011, p. 159) enfatiza que é essencial notar que aquele não se fixa apenas em diretrizes gerais a serem posteriormente materializadas em normas urbanísticas. Deve estabelecer concretamente as diretrizes do território urbano, reunindo os elementos necessários para defini-la. Destarte, a ordenação deve contar com a possibilidade de desastres naturais e adequar seu plano diretor de forma que este traduza as necessidades mais prementes.

O artigo 41 do Estatuto da Cidade, após a edição da Lei nº 12.608, de 2012, em seu inciso VI, obriga a elaboração de plano diretor a todas as cidades "incluídas no cadastro nacional de Municípios com áreas suscetíveis à ocorrência de deslizamentos de grande impacto, inundações bruscas ou processos geológicos ou hidrológicos correlatos. 
Em suas ilações acerca do plano diretor, José Afonso da Silva (2012, p. 150), afirma acertadamente que o conteúdo e bases do plano urbanístico desmistificado não passam do estabelecimento de diretrizes básicas da ordenação físico territorial municipal, que costuma ser seguido por um conjunto de mapas e plantas. Em uma cidade sujeita a desastres naturais é simples observar que nesses mapas e plantas constarão as fragilidades daquela circunscrição e os locais que devem ser evitados no que tange, sobretudo, ao estabelecimento de populações de baixa renda.

\section{A EDIÇÃO DA MP Nº 547, DE 2011, CONVERTIDA NA LEI No 12.608, DE 2012}

Os desastres naturais ocorridos repetidamente afetaram efetivamente a forma de vida de diversas cidades brasileiras, sobretudo naquelas em que se observou o deslizamento de encostas. Isso comprova que uma administração omissiva por parte dos poderes públicos mais e mais agravariam a situação dessas cidades. Assim, novas políticas urbanas deveriam ser incorporadas ao planejamento local para que novos mecanismos de prevenção e diminuição de impactos fossem efetivamente incorporados na rotina daqueles municípios afetados por chuvas torrenciais.

A possível prevenção dessas ocorrências impactantes demandaria a adoção de uma gestão de riscos mais completa por parte de diversos atores sociais, que não estaria apenas reduzida ao âmbito regional ou local. Essa redução demandaria uma ação mais efetiva em prol das populações que estivessem envolvidas em ocupações urbanas já instaladas, mormente em locais em que as precipitações levassem todos a uma preocupação pontual.

Na exposição de motivos da Medida Provisória n 547, de 2011, é esclarecido que "a efetivação dessa abordagem integrada da gestão de riscos exige a atuação articulada dos três níveis de governo, na esfera de suas competências e a definição de medidas claras para o enfrentamento do problema [...]. Isto geraria uma inter-relação entre planejamento e a gestão do espaço urbano com as condicionantes do meio físico.

A edição desta Lei superou uma etapa complexa na legislação nacional. Não obstante, como já esclarecido, existissem outros diplomas que cuidavam da matéria passou a ser um novo marco regulatório do tema, que inclusive instituiu um sistema nacional, criou um conselho. Essa nova formação normativa ocorreu um ano após o desastre hidrológico que ceifou muitas vidas na região serrana do Estado do Rio de Janeiro.

Rev. de Direito Urbanístico, Cidade e Alteridade | e-ISSN: 2525-989X | Porto Alegre | v. 4 | n. 2 | p. 85 - 100 | Jul/Dez. 2018 
O Instituto Brasileiro de Geografia e Estatística esclareceu, em 2010, que mais de 84\% da população vivia em áreas urbanas, e este número tendia apenas a crescer. Em publicação recente produtos do Acordo de Cooperação Técnica, firmado em 2013, entre o Instituto Brasileiro de Geografia e Estatística - IBGE e o Centro Nacional de Monitoramento e Alertas de Desastres Naturais - CEMADEN (2018), reuniram-se esforços e ações em prol do desenvolvimento de pesquisas aplicadas para a geração de bases de dados e informações associadas à caracterização das populações vulneráveis a desastres naturais no território brasileiro.

Nesta publicação (2018) deixou-se claro que, no contexto da estruturação de um sistema de monitoramento e alerta de desastres naturais é fundamental "a identificação e a caracterização da população residente em áreas de risco". Além disso, informações geográficas são fundamentais para subsidiar ações de redução de danos humanos, ambientais, sociais e econômicos.

O que seria realmente importante para se traçar um panorama seguro com a finalidade de se identificar as áreas sujeitas a desastres importaria em uma verificação da distribuição espacial e características da população exposta e vulnerável em áreas de risco. Certamente estes dados não estão disponíveis em escala nacional. O IBGE buscou uma metodologia integrando as informações oriundas do Censo demográfico e dos mapeamentos de áreas de risco de desastres no Brasil, sem correspondência espacial entre os setores censitários, as faces de quadra e as áreas de risco. Esta nova fórmula registrou inúmeras tabelas e mapas de resultados, correspondentes aos dados referentes ao Censo Demográfico 2010 e às áreas de risco a desastres naturais, além de breve análise da população exposta em áreas de riscos.

É fundamental que haja uma fiscalização efetiva do uso e ocupação do solo para que se evitem ocorrências imprevistas e possam coibir a especulação imobiliária, que bem gerando retrocessos significativos em todas as cidades. Também é importante a implementação de políticas públicas capazes de suprir habitação popular em áreas adequadas. A Lei no 12.608 , de 2012, publicada sob a comoção do ocorrido na Região Serrana do Estado do Rio de Janeiro, veio efetivamente para contribuir com a busca de ações efetivas, como a implementação do Serviço Militar Alternativo no combate a tragédias, entre outras alternativas viáveis diante de tragédias por desabamentos ou catástrofes climáticas. 


\section{PLANOS DIRETORES EFETIVOS RELACIONADOS A CIDADES COM DESASTRES NATURAIS}

A população hodierna se estabeleceu de forma a viabilizar uma urbanização espontânea e o despovoamento do campo. Seguiram esses processos o desgaste dos recursos naturais, com ação antrópica sem qualquer cuidado, acompanhada por ampla e crescente desconsideração do frágil ambiente que diante do nivel de poluição alcançado, nos anos setenta, diante de sua esgotabilidade próxima ameaçando condições de vida, indivíduos e sociedades, deu azo à ocorrência de conferências internacionais organizadas em prol da sustentabilidade desses escassos recursos naturais fundamentais para as presentes e futuras gerações.

As diversas populações existentes foram informadas das condições e das preocupações sérias que deveriam se materializar em formas adequadas de um tratamento adequado do ambiente. Essas mudanças permitiram o surgimento do termo "sustentabilidade" para que a sociedade pudesse assumir comopromisso com sua propria subsistência. Nesse sentido, a comunidade global foi estimulada a levar a sério os objetivos de desenvolvimento social e ambiental na inovadora conferência sobre desenvolvimento sustentável, organizada pelas Nações Unidas no Rio de Janeiro em 2012. "Os objetivos de desenvolvimento sustentável" (ODS), denominado "Transformando nosso mundo: a agenda 2030 para o desenvolvimento sustentável", foram adotados. Desde então os compromissos assumidos em forma de "agendas" foram discutidos e implementados, de um forma ou outra, pelos estados membros das Nações Unidas. É relevante analisar criticamente a implementação parcial dessas obrigações nas sociedades e no meio ambiente, e refletir sobre os conflitos sociais e ambientais em andamento.

Como bem sublinha Guido Soares (2005, p. 645-716), o mais importante que se pode ressaltar na ECO-92 é a consagração do conceito de "desenvolvimento sustentável”, que já se encontravam de alguma forma reafirmados nas duas Convenções adotadas durante a Conferência da ONU. Esse conceito, de extrema relevância, deixou sua marca no direito e atualmente imprime diversas responsabilidades aos Estados, mormente quando se trata de danos ambientais.

O autor segue em sua ilação afirmando que a questão das ações futuras relacionadas ao ambiente estariam nas futuras "agendas" que buscariam estabelecer as priopridades. Haveria, portanto, mecanismos capazes de acompanhar as atividades que os Estados se propusessem a desenvolver sempre com vistas à proteção do ambiente global e que deveriam estar associadas a todos os níveis de desenvolvimento pleno do homem, não se permitindo dissociar os aspectos

Rev. de Direito Urbanístico, Cidade e Alteridade | e-ISSN: 2525-989X | Porto Alegre | v. 4 | n. 2 | p. 85 - 100 | Jul/Dez. 2018 
preservacionistas do ambiente local ou global, daqueles mais gerais relacionados às condições sociais e políticas dos povos.

Essa nova forma de tratamento da economia, com fórmulas de planejamento, estabelecimento de médias em curto, médio e longo prazo, tratamento apropriado do ambiente, indicação de ações, busca de apoio, metas de desenvolvimento do homem de forma a viabilizar melhor qualidade de vida, mediante sistemas distributivos próprios, imprimiu uma formatação moderno dos planos diretores, que deixaram de estar apenas adstritos à distribuição social adequada do espaço municipal. Isso certamente traz melhor qualidade de vida para os municípios. A questão municipal ganhou cada vez maiores perspectivas gerando, inclusive, a formação de organizações e associações em prol dessa meta, o que inclusive formatou a expressão "cidades sustentáveis" e até mesmo e possibilidade de se alcançar a "função social da cidade", tal como forjou o constituinte brasileiron no texto do art. 182 da Constituição brasileira.

A gestão de risco de desastres é de grande importância no desenvolvimento territorial no Brasil, devendo em consequência estabelecer uma estreita relação com as diretrizes decorrentes da aplicação de instrumentos governamentais de planejamento e gestão, tal como o Plano Diretor Municipal (PDM).

Os objetivos e as diretrizes do plano diretor, como bem delimitou Jakuboski, Rauber e Leite Cabral (2016), são fundamentais tanto para uma melhor qualidade de vida para a população quanto para o desenvolvimento das cidades. O Poder Público tem o dever de cumprir com o seu dever de implantar o que for aprovado na lei do Plano Diretor do Município. Nesse sentido, o Poder Público deve se empenhar em aplicar os objetivos e as diretrizes que o Plano Diretor possui, com o intuito de desenvolver as cidades de maneira sustentável e adequada, reduzindo os pontos negativos por meio de uma reforma urbana. Importante sublinhar que o Estatuto da Cidade, em seu artigo 39 exige que o imóvel não só satisfaça o quesito econômico, exige ainda que atenda às exigências fundamentais expressas no Plano Diretor. Esse dispositivo permite inferir que a necessidade não se restringe apenas a um viés econômico, mas também satisfaça outras necessidades municipais.

No âmbito das cidades com vulnerabilidades identifica-se que a gestão de risco de desastres é de grande importância no desenvolvimento territorial no Brasil. Portanto, deve-se em consequência estabelecer uma estreita relação com as diretrizes decorrentes da aplicação de instrumentos governamentais de planejamento e gestão, tal como o Plano Diretor Municipal. 
A atualidade comprova que os planos diretores são fundamentais e obrigatórios em locais em que haja gestão de risco de desastres relacionados com fenômenos naturais. Este é o inciso VI do art. 41 do Estatuto da Cidade incluído por meio da Lei n. 12.608, de 2012, que se caracteriza como um instrumento jurídico que amplia as redes de interação entre a sociedade e agentes públicos em diversos níveis. Busca aumentar a eficiência das ações governamentais no estabelecimento de políticas de prevenção e gerenciamento de riscos de desastres. Esta norma instituiu também a Política Nacional de Defesa Civil - PNPDEC, que dispõe sobre o sistema de informações e monitoramento de desastres que deve se integrar às políticas de ordenamento territorial, urbano, saúde, meio ambiente, mudanças climáticas, gestão de recursos hídricos, geologia, infraestrutura, educação, ciência e tecnologia e às demais políticas setoriais, tendo em vista a promoção do desenvolvimento sustentável.

\section{4 - QUADRO ATUAL DAS VULNERABILIDADES E A EFETIVIDADE DA PNPDEC}

A região sudeste é certamente a que possui maior frequência de desastres relacionados a tempestades. O aquecimento global tem sido o grande responsável por esses eventos (2012). Segundo registros do CEPED (2011), no Brasil, aproximadamente 60\% dos desastres identificados são classificados como de origem climáticas, com predominância da estiagem e da seca atingindo mais de 50 milhões de brasileiros.

Nos termos estabelecidos na Lei 12.608, de 2012, quatro atores fundamentais são reconhecidos, com seus papéis bem delineados: União, Estado, Município e sociedade. Cada ente da Federação possui ainda outras corporações integrantes que se aliam no combate a desastres e problemas que possam ocorrer.

A Política Nacional de Proteção e Defesa Civil dispõe expressamente sobre o Sistema Nacional de Defesa Civil (SINDEC). Este deve repassar recursos para ações de socorro e assistência às vítimas, como atribuição fundamental. Sob essa perspectiva de gestão, o SINDEC passou a atuar nas ações de prevenção de desastres, mitigação de riscos, preparação, resposta e recuperação, e passou a denominar-se Sistema Nacional de Proteção e Defesa Civil - SINDPEC. A modificação gerou uma nova estruturação capaz de estabelecer fórmulas próprias em prol de atividades de prevenção em detrimento das práticas compensatórias.

$\mathrm{O}$ art. 22 da PNPDEC alterou a Lei no 12.340/2010, inserindo o art. $3^{\circ} \mathrm{A}$, em que estabelece a obrigatoriedade do Governo Federal instituir cadastro nacional de áreas suscetíveis à ocorrência de deslizamentos de grande impacto, inundações bruscas ou processos geológicos

Rev. de Direito Urbanístico, Cidade e Alteridade | e-ISSN: 2525-989X | Porto Alegre | v. 4 | n. 2 | p. 85 - 100 | Jul/Dez. 2018 
ou hidrológicos correlatos. O município deve solicitar essa inscrição. Após esses procedimentos passos devem ser dados pelo poder local. A Lei, não contém prazo ou sanções para o inadimplemento.

A política de proteção e defesa civil deve se inserir no contexto das políticas de ordenamento das cidades contemplando o desenvolvimento urbano, ambiente, saúde, infraestrutura, educação, gestão em recursos hídricos etc. Deve efetivamente contribuir para que as cidades possam alavancar-se e ter seu desenvolvimento garantido, não obstante suas peculiaridades próprias que as incluem na categoria prevista na Lei 12.608/2012. Há dois vetores que devem ser objeto de atenção, nos termos da cartilha do Ministério Público de São Paulo sobre áreas de risco, com o objetivo de subsidiar a atuação dos membros do MP no enfrentamento desse tema (2017). Um dos vetores está relacionado com o planejamento que deve contemplar uma atuação preventiva de forma a identificar os locais em que não se recomenda a urbanização ou ainda nos locais em que esta apenas seria viável mediante a realização de obras determinadas. De outro, um vetor em que se prevê uma atuação mitigadora em que se identificasse locais já ocupados expostos a situação de riscos de desastres.

Na questão preventiva é imprescindível que o Município exerça seu poder de polícia, dificultando a ocupação em áreas consideradas impróprias para uso e que realmente possam sofrer deslizamento ou desmoronamento. Deve, portanto, ser cauteloso na tomada de medidas para evitar essa ocupação que poderia culminar com a perda de vidas e outras ocorrências que se quer evitar. Nesse sentido, o plano diretor para os municípios incluídos no cadastro nacional de municípios com áreas suscetíveis à ocorrência de deslizamentos de grande impacto, inundações bruscas ou processos geológicos ou hidrológicos correlatos já demarca áreas sujeitas a alagamentos e áreas em que desastres podem ocorrer.

No tocante a atuação responsiva, como também instrui adequadamente a Cartilha do MP-SP (2017) não se deve concluir imediatamente que uma área ocupada considerada como sujeita a algum desastre natural deva ser desocupada imediatamente. É notório que as normas atuais, aí se inclui a Lei $\mathrm{n}^{\circ} 13.465$,de 2017 , buscam a regularização no local da ocupação. A remoção sé deveria ser efetivada quando nenhuma outra medida pudesse ser tomada em termos de contenção ou ainda na hipótese do eventual insucesso das medidas corretivas tomadas previamente, que não geraram os efeitos previstos.

O esquema estabelecido para a prevenção dos desastres naturais viabilizou o surgimento de novos instrumentos de auxílio para a consolidação dos programas. Entre eles, criou-se o Centro de Monitoramento de Desastres Naturais (CEMADEN), em 2012. Nas 
palavras de Silva et al. “[...] tem o objetivo de desenvolver um sistema de previsão de ocorrência de desastres naturais no território nacional e apontar vulnerabilidades no uso e ocupação do solo para o planejamento urbano."

O monitoramento auxiliado pelo CEMADEN exige que a municipalidade apresente o mapeamento das áreas de risco e seus limites territoriais considerados vulneráveis para deslizamentos de encostas, enxurradas, enchentes, dentre outros. Tudo isso pode ainda ser auxiliado pela ação conjunta de diversos Ministérios, conforme ainda prevê a Lei 12.608, de 2012, para a criação de um programa que tenha na prevenção a principal fórmula de atuação com a somatória das diversas experiências dos atores envolvidos. É fundamental que essa discussão se dê de forma ampla com os setores que puderem contribuir com sua experiência.

\section{CONSIDERAÇÕES FINAIS}

A coordenação do Sistema Nacional de Proteção e Defesa Civil no Brasil é da União, que sugere as ações apropriadas a serem tomadas em articulação com estados, municípios e munícipes. No corpo do trabalho as pesquisas confirmar que as mudanças climáticas, sobretudo na Região Sudeste, ora geram excesso de chuvas ou estiagem rigorosa, demandam atuação pronta da sociedade civil a fim de se evitar os correspondentes desastres naturais. Essas ações não podem se desvincular de uma gestão de riscos permanente, em que se garanta o estabelecimento de medidas voltadas à prevenção e eliminação de desastres naturais, isso sem mencionar no permanente estudo voltado à diminuição dos fatores de risco. As vulnerabilidades sociais também devem ser avaliadas no processo de elaboração do planejamento urbano na municipalidade com a contemplação de solução de eventuais problemas socioeconômicos.

Os processos reiterados de ocupações comprovam a desviculação de legisladores e administradores antecedentes na possível solução os problemas sociais. Estes se agravaram e aceleraram pelas interações de grupos que realmente necessitam e por outros que buscam apoios em posições ilegais.

Diante desse quadro se esclarecer que a Lei da Política Nacional de Proteção e Defesa Civil - PNPDEC, introduzida por meio da Lei $n^{\circ}$ 12.608, de 10 de abril de 2012, trouxe mecanismos de apoio e proteção aos municípios necessitados. É possível verificar, em processos contínuos, se a prevenção, mitigação, preparação, resposta e recuperação relacionadas à proteção e a defesa civil estão sendo efetivamente tomadas. Há dificuldades naturais na implementação do plano que, além de considerar todas as variáveis territoriais, deve

Rev. de Direito Urbanístico, Cidade e Alteridade | e-ISSN: 2525-989X | Porto Alegre | v. 4 | n. 2 | p. 85 - 100 | Jul/Dez. 2018 
estar voltado para o futuro e assim contemplar aspectos econômicos e sociais relevantes para a municipalidade. Os atores efetivamente envolvidos são: União, estados, municípios e sociedade. Também se podem incluir novos agentes já que as regiões metropolitanas estão consignando nos respectivos planos diretores urbanos integrados (PDUI) as vulnerabilidades da circunscrição territorial em que se radicam seus municípios integrantes. A melhoria do processo de defesa das catástrofes climáticas pode ser estruturada com equipes treinadas e com uma definição dos agentes e suas respectivas funções nas hipóteses de emergência.

A atuação municipal ou mesmo de entidades que possam auxiliar nesse mister deve ser no sentido preventivo e repressivo. A primeira atuação deve ser no momento em que há intenção de ocupação. Por meio do poder de polícia, o município deve evitar/negar a permanência de pessoas em áreas consideradas inadequadas pelo plano diretor local, que deve obrigatoriamente existir, por força do que dispõe o art. 41, VI da Lei 10.257, de 2001. Esse instrumento já teve sua análise prévia pelos especialistas, geólogos e outros técnicos que mapearam a circunscrição municipal consignando as áreas de risco.

Há outra atuação, que é a mais comum, a responsiva, em que a ocupação já ocorreu e a municipalidade não teve chance de impedir no momento apropriado. Nestes casos, a atuação deve ser no sentido de garantir a permanência, por meio de medidas mitigadoras e outras que possam garantir a segurança das pessoas envolvidas. Caso as medidas tomadas se mostrem inefetivas diante dos desastres ocorridos, outra hipótese não há que o deslocamento dessas pessoas para locais em que possam estar seguras.

Nos termos do Sistema Nacional de Defesa Civil, a Lei n. 12.340/2010 ainda estabelece mecanismos para que a União auxilie os demais entes da Federação na elaboração de projetos de prevenção de riscos e na execução de ações de recuperação e resposta a desastres. A fim de receber recursos destinados à execução de ações de recuperação e resposta é fundamentla que o próprio Executivofederal reconheça essa situação de emergência ou de calamidade. O Estado ou Município afetado podem apresentar projetos à União, para que, aprovando-os, efetuará os repasses de recursos e fiscalizará o cumprimento das metas e ações propostas. 


\section{REFERÊNCIAS}

AFONSO DA SILVA, José. Dieito urbanístico brasileiro. São Paulo: Ed. Malheiros, 2012.

BRASIL (2017/2018). Ministério da Integração Nacional. Histórico da defesa civil. Disponível em < http://www.integracao.gov.br/historico-sedec>. Acesso em 26.08.2018.

BRASIL (2011/2012). Ministério da Integração Nacional. Anuário Brasileiro de Desastres Naturais. Centro Nacional de Gerenciamento de Riscos e Desastres - CENAD, Brasília.

CÂMARA, Jacinto Arruda. Plano diretor. In Estatuto da Cidade: comentários à Lei 10.257, de 2001. Orgs. DALLARI, Adilson A. e FERRAZ, Ségio. São Paulo: Ed. Malheiros, 2014.

CARVALHO PINTO, Victor. Direito urbanístico: plano diretor e direito de propriedade. Sao Paulo: Ed. Revista dos Tribunais, 2011.

CEPED (2011). Atlas brasileiro de desastres naturais 1991 a 2010: Volume Brasil. Florianópolis: CEPED UFSC.

ESPÍRITO SANTO. Celina Marques do e SZLAFSZTEIN, Claudio Fabian. Gestão de risco de desastres em planos diretores de três municípios da zona costeira do Estado do Pará. Revista da Gestão Integradar Disponível em http://www.scielo.mec.pt/scielo.php?script=sci_arttext\&pid=S1646-88722016000200009>. Acesso em 25.08.2018.

IBGE. População em áreas de risco no Brasil. Rio de Janeiro, 2018. Disponível em < https://www.ibge.gov.br/apps/populacaoareasderisco/> . Acesso em 26.08.2018.

JAKUBOSKI, Adriélli Pelizzar; RAUBER, Elton Antonio; CABRAL, Francisco Leite. Estatuto da Cidade e plano diretor: o que são e para que servem. Disponível em < http://www.site.ajes.edu.br/congre/arquivos/20160823223200.pdf >. Acesso em 26.08.2018.

MEIRELLES, Hely Lopes. Direito municipal brasileiro. São Paulo: Ed. Malheiros, 1985.

OLIVEIRA, Regis Fernandes. Comentários ao Estatuto da Cidade. São Paulo: Ed. Revista dos Tribunais, 2005.

SAADI, A. A geomorfologia como ciência de apoio ao planejamento urbano em Minas Gerais. In: Simpósio brasileiro de geografia física aplicada. $1^{\circ}$ Fórum Latino-Americano de geografia física aplicada. V.2. Curitiba: UFPR, 1997.

SÃO PAULO. Ministério Público. Áreas de risco. Disponível em < http://www.mpsp.mp.br/portal/page/portal/Cartilhas/AreasDeRisco.pdf>. Acesso em 27.08.2018.

SILVA Augusto César Pinheiro da; PINTO, Rodrigo Wagner Paixão e FREITAS, Marcelo Motta de. Avaliação de políticas públicas relacionadas aos desastres naturais no Brasil entre

Rev. de Direito Urbanístico, Cidade e Alteridade | e-ISSN: 2525-989X | Porto Alegre | v. 4 | n. 2 | p. 85 - 100 | Jul/Dez. 2018 
1990 - 2014. Disponível em <file://C:/Users/EDSON/Downloads/3246-21547-2-PB.pdf>. Acesso em 26.08.2018.

SOARES, Guido Fernando Silva. Direito ambiental internacional. In Curso Interdisciplinar de direito ambiental. Orgs. PHILIPPI JR, Arlindo e ALVES, Alaôr Caffe. Barueri: Manole, 2005.

ULTRAMARI, Clovis e REZENDE, Denis Alcides. Plano diretor e planejamento estratégico municipal: introdução teórico-conceitual. RAP Rio de Janeiro 41(2):255-71, Mar./Abr. 2007. Disponível em < http://www.scielo.br/pdf/rap/v41n2/05.pdf>. Acesso em 29.07.2018 